\title{
Combined Major and Trace Element Characterization of Tourmaline: Using EPMA to Address Elemental Fractionation by Laser Ablation
}

\author{
Jared Wesley Singer $^{1}$ and Marian Lupulescu ${ }^{2}$ \\ 1. Earth and Environmental Science, Rennselaer Polytechnic Institute, Troy, NY, USA. \\ 2. Research and Collections, New York State Museum, Albany, NY, USA.
}

Electron Probe Microanalysis (EPMA) and Laser Ablation Inductively Coupled Plasma Mass Spectrometry (LA-ICPMS) synergistically reinforce the accuracy and precision of the other. EPMA is a classic technique of X-ray microanalysis, but is subject to limitations in regards to light elements $(\mathrm{H}, \mathrm{Li}$, and $\mathrm{Be}, \mathrm{B}$ ) and trace element sensitivity. On the other hand LA-ICPMS is sensitive for trace element analysis and it is possible to measure Li and B. However, accuracy of LA-ICPMS hinges on internal standard (IS) compositions from EPMA and quantifiable fractionation behaviors. In this paper we present a method for total compositions using a fully-integrated EPMA/LA-ICPMS analytical strategy. EPMA provides an essential, independent analysis of laser ablation accuracy.

Major element determinations were made by EPMA, using CAMECA model SX-100. Column settings included a $15 \mathrm{kV}$ accelerating voltage, 20nA regulated beam current, and 5 micron spot size. Major element compositions were corrected in an iterative manner for $\mathrm{Li}, \mathrm{B}, \mathrm{H}$, and $\mathrm{O}$ by stoichiometric formula recalculation of Selway and Xiong and the ZAF-type algorithm of Pouchou and Pichoir. Convergence is obtained in 3 or less iterations. Ideal totals within $1 \%$ were obtained for diverse species including elbaite, schorl, dravite, uvite, foitite and fluoro- tourmalines. Trace elements were measured by LA-ICPMS using a PhotonMachines Analyte.193, 4ns pulse, eximer laser coupled to a Varian 820 quadrupole ICP-MS. Spot analyses were conducted at $48 \%$ laser power, repetition rate $6 \mathrm{~Hz}, 60 \mathrm{~s}$ duration, spot size $80 \mathrm{um}$ square, and laser fluence of $4.95 \mathrm{~J} / \mathrm{cm}^{2}$. Time-dependent laser fractionation experiments were conducted under similar conditions for 300 s durations. Helium carrier gas flowing at $0.70 \mathrm{~L} / \mathrm{min}$ transports the ablated aerosol to ICPMS under dry, hot plasma conditions. IS concentrations from EPMA are specified for ${ }^{23} \mathrm{Na},{ }^{27} \mathrm{Al}$, and ${ }^{29} \mathrm{Si}$ and concentrations are determined against NIST612 glass. Instantaneous fractionations $\left(\mathrm{R}_{\mathrm{i}}\right)$ of major elements by laser ablation are calculated through direct comparison of LA-ICPMS spot analysis to results of EPMA for multiple internal standards $\left(\mathrm{R}_{\mathrm{i}}=[\mathrm{C}]_{\mathrm{LA}(\mathrm{IS})} /[\mathrm{C}]_{\mathrm{EPMA}}\right.$; table 1$)$. Time-dependent fractionation $\left(\mathrm{R}_{\mathrm{t}}\right)$ is calculated by the ratio of the initial to the final half of a 300s ablation $\left(\mathrm{R}_{\mathrm{t}}=[\mathrm{C}]_{\mathrm{i}} /[\mathrm{C}]_{\mathrm{f}} ;\right.$ Figure 1$)$.

Major element data obtained by both EPMA and LA-ICPMS demonstrates large systematic errors (ranging $>50 \%$ ) that result from laser ablation processes. Instantaneous fractionations (depletions) are observed in the order $\mathrm{F}>>\mathrm{B}>\mathrm{Fe}>\mathrm{Mn} \sim \mathrm{Na}>\mathrm{Li}>\mathrm{Si}>\mathrm{Al}>\mathrm{Ca}$ (Table 1). Detailed analysis is given here for one elbaite specimen, demonstrating that time-dependent fractionation is not a suitable proxy for instantaneous fractionation (compare Table 1 and Figure 1); furthermore various tourmaline species show a diversity of time-dependent fractionations. For trace element determinations the magnitude of systematic error strongly depends on the choice of internal standard, however the analyst cannot know a priori which combination of analyte/IS is most appropriate. Fractionation behaviours of other tourmaline species and reference glasses will remain an area of continued research toward a multiple-IS correction scheme for accurate trace element data. Ongoing investigation includes composition of ablation ejecta (figure 2), dependence on laser fluence, crystal orientation dependence, and mechanisms of elemental fractionation during laser ablation. 


\begin{tabular}{|c|c|c|c|c|c|c|c|}
\hline \multirow[b]{2}{*}{ Element } & \multirow[b]{2}{*}{ EPMA } & \multicolumn{6}{|c|}{ Instantaneous Fractionation Factor $\left(\mathrm{R}_{\mathrm{i}}=[\mathrm{C}]_{\mathrm{LA}} /[\mathrm{C}]_{\mathrm{EPMA}}\right)$} \\
\hline & & $\mathrm{R}(\mathrm{Na}$ IS) & $\pm \sigma$ & $\mathrm{R}(\mathrm{Al} \mathrm{IS})$ & $\pm \sigma$ & $\mathrm{R}$ (Si IS) & $\pm \sigma$ \\
\hline $\mathrm{Li}$ & 0.92 & 1.23 & \pm 0.03 & 0.88 & \pm 0.05 & 1.04 & \pm 0.02 \\
\hline B & 3.47 & 0.80 & \pm 0.03 & 0.56 & \pm 0.05 & 0.69 & \pm 0.02 \\
\hline $\mathrm{F}$ & 0.93 & 0.023 & \pm 0.44 & 0.016 & \pm 0.43 & 0.020 & \pm 0.42 \\
\hline $\mathrm{Na}$ & 1.39 & 1.00 & & 0.70 & \pm 0.06 & 0.84 & \pm 0.03 \\
\hline $\mathrm{Al}$ & 22.77 & 1.44 & \pm 0.06 & 1.00 & & 1.24 & \pm 0.05 \\
\hline $\mathrm{Si}$ & 16.02 & 1.29 & \pm 0.03 & 0.89 & \pm 0.05 & 1.00 & \\
\hline $\mathrm{Ca}$ & 0.28 & 1.49 & \pm 0.15 & 1.01 & \pm 0.16 & 1.27 & \pm 0.15 \\
\hline $\mathrm{Mn}$ & 0.293 & 1.00 & \pm 0.02 & 0.70 & \pm 0.04 & 0.83 & \pm 0.02 \\
\hline $\mathrm{Fe}$ & 0.05 & 0.86 & \pm 0.21 & 0.63 & \pm 0.22 & 0.75 & \pm 0.21 \\
\hline $\mathrm{H}$ & 0.38 & & & & & & \\
\hline $\mathrm{O}$ & stoichiometric & & & & & & \\
\hline Total & 100.10 & & & & & & \\
\hline
\end{tabular}

Table 1. Major and minor elements of elbaite as determined by EPMA and instantaneous fractionation factors for LA-ICPMS are calculated from 60 s spots for various IS $\left({ }^{23} \mathrm{Na},{ }^{27} \mathrm{Al}\right.$, and $\left.{ }^{29} \mathrm{Si}\right)$. Note that by definition, EPMA and LA-ICPMS are in agreement when $\mathrm{R}=1.0$

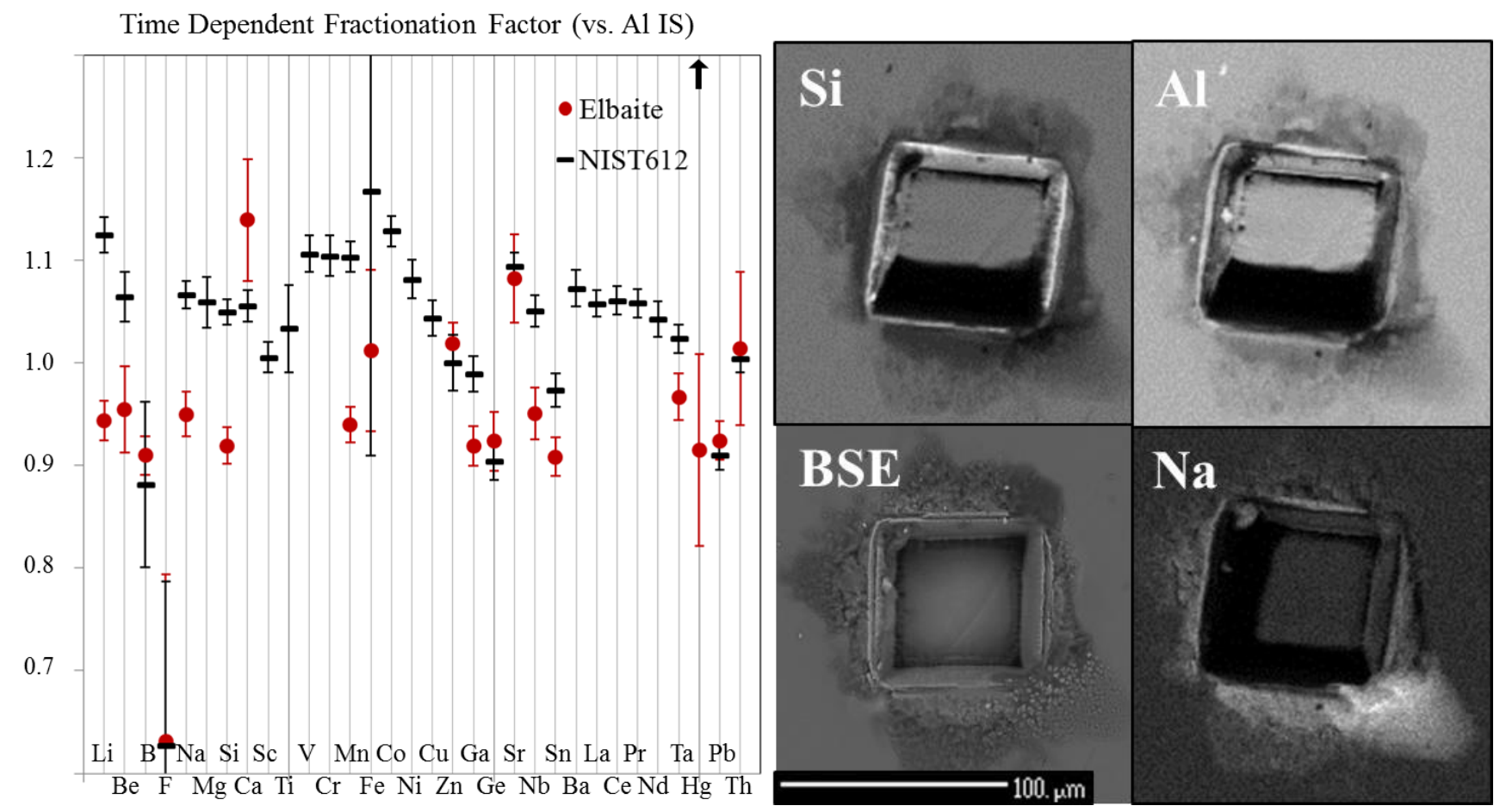

Figure 1. Left: Time-dependent fractionation factors of elbaite (circle) and NIST612 (bar) show marked differences (Al IS; $\mathrm{Al}=1.0$ ). Except for $\mathrm{F}$ and $\mathrm{Hg}$, time dependent fractionations are smaller than instantaneous fractionations. Right: X-ray maps of the elbaite ablation pit (300s) shows Na enrichment in ejecta relative to $\mathrm{Al}$ and $\mathrm{Si}$. 